\title{
STUDIES ON THE ROLE OF TUMOR NECROSIS FACTOR- ALPHA (TNF- $\alpha$ ) IN HEPATOCYTES INDUCED APOPTOSIS IN VACCINATED, SCHISTOSOMA MANSONI-CHALLENGED MICE
} By

SAMIA E. ETEWA ${ }^{1}$, NAGLAA F. ABD EL-AAL ${ }^{1}$, SARA A. ABDELRAHMAN ${ }^{1}$,EMAN H. ABD EL BARY ${ }^{2}$ AND MAHMOUD A. EL-SHAFEl ${ }^{3}$ Departments of Medical Parasitology ${ }^{1}$, Pathology ${ }^{2}$, Clinical Pathology ${ }^{3}$, Faculty of Medicine, Zagazig University, Zagazig, Egypt

\section{Abstract}

Tumour Necrosis Factor-alpha (TNF- $\alpha$ ) plays a complex role in pathophysiological changes caused by schistosomiasis in the liver cells as induced apoptosis. So, The highlighted experimentally the role of TNF- $\alpha$ in hepatocytes apoptosis, using that as an assessment of the efficacy of antischistosomal vaccination by mixed crude antigens preparations [Cercarial antigen preparation $(\mathrm{CAP})+$ soluble worm antigen preparation $(\mathrm{SWAP})+$ soluble egg antigen(SEA)] by parasitological, histo-pathological and histochemical studies using Feulgen stain of hepatoytes DNA, a serological study also of serum TNF- $\alpha$ level by ELISA. Fifty two laboratory bred Albino male mice, were used in this study. They were classified into four groups (13 mice in each group), G1: normal control, G2 as infected control while G3 supported by Freund's Adjuvant (F. Adj) then infected and G4 vaccinated with combined antigens (CAP, SWAP and SEA) + F. Adj, then infected. Mice were sacrificed by cervical dislocation 9 weeks post infection, parasitological (Kato-Katz thick smear for egg count), histopathologial \{haematoxylin and eosin (H\&E) staining of hepatic sections\}, histochemical (feulgen staining of hepatocytes DNA) and ELISA to estimate serum TNF- $\alpha$ level were performed.

The data showed that vaccination with combined antigens showed protective effect on vaccinated then Schistosoma challenged mice, hepatocytes induced apoptosis was directly proportional with the TNF- $\alpha$ serum level, and the protection degree of potential combined vaccine was inversely proportional with serum TNF- $\alpha$ level and induced apoptosis.

Keywords: S. mansoni, TNF- $\alpha$, CAP, SWAP, SEA, feulgen stain, apoptosis.

\section{Introduction}

Schistosomiasis being a major source of morbidity and mortality for developing countries in Africa, South America, the Caribbean, the Middle East, and Asia (WHO, 2010). S. mansoni infections are associated with the chronic local inflammatory response to schistosome eggs trapped in host tissues (Fairfax et al, 2012) which may lead to intestinal disease, hepatosplenic inflammation, and liver fibrosis (Gryseels et al, 2006) During the first 4-5 weeks following exposure to cercariae, immune response is primarily Th1 against the cercariae, schistosomula and the worm antigens. However, as the eggs are produced by the parasites the immune response changes to Th2-polarized (Pearce, 2005). This Th2 response induced circumoval granulomas, which are more or less rich in the eosinophils and collagen fibers (Reiman et al, 2006). The deposition of eggs in liver induces a severe inflammatory reaction, which participates in disintegration of eggs but may cause damage of DNA and liver cell apoptosis (Sayed et al, 2006).

Apoptosis is defined morphologically by the presence of cytoplasmic shrinkage (pyknosis), chromatin condensation, the nuclear fragmentation (karyorhexis), the presence of plasma membrane blebbing and the maintenance of an intact plasma membrane which retains its integrity as the cell fragments into apoptotic bodies (Kroemer et al, 2005), which are then removed by the phagocytosis (Thornberry, 1998). Apoptosis is a highly regulated form of cell death, with multiple check 
points and molecular mediators. The apoptosis occurring during development and ageing is the genetically regulated and therefore the term programmed cell death is used to describe apoptosis. Unlike developmental apoptosis which is carefully regulated in a spacio-temporal pattern and does not involve secondary events, the pathologic apoptosis is unregulated and can be massive (Rutherford et al, 2007). Nevertheless, the hepatocytes pathological apoptosis is the initial cellular response to injury and may thus initiate several, intertwined cellular and cytokine cascades that culminate in tissue injury, inflammation, fibrosis and finally, in hepatic cirrhosis (KilIcarslan et al, 2009).

In schistosomiasis, apoptosis may be used as a survival strategy to establish infection in their host, and may influence the development or maintenance of different clinical manifestations (Lundy et al, 2001). In schistosomiasis regulation of apoptosis in hepatocytes is complex and is commonly triggered through activation of death receptors (DRs) (Gores and Kaufmann, 2001).

Tumor necrosis factor- $\alpha$ (TNF- $\alpha)$ is an inflammatory cytokine that is released by injured hepatocytes. It activates stellate cells and Kupffer cells and recruits activated $\mathrm{T}$ cells. These cells secrete numerous cytokines and stimulate each other in a persistent inflammatory cycle that leads to liver fibrosis (Rimkunas et al, 2009). Hepatocytes express both tumor necrosis factor receptor1 (TNFR1), and tumor necrosis factor receptor 2 (TNFR2), though their functional significance differs (Yamada et al, 1998). TNFR1 is thought to mediate most of the biologic effects of TNF- $\alpha$; it expresses a cytoplasmic death domain and executes the apoptotic program by interacting with adaptor proteins (Hsu et al, 1995).

TNF- $\alpha$ may participate in the granuloma formation and evolution of fibrotic tissue process Hoffmann and colleagues (1998), they have also demonstrated in the experimental models that TNF- $\alpha$ exerts the protective effect. Whereas the other authors attribute to the TNF- $\alpha$ proinflammatory and profibrogenic effects (Ramadan et al, 2013). It is one of the cytokines that plays also an important role in regulation of the inflammatory granulomatous response in the schistosomiasis (Singh et al, 2004).

TNF- $\alpha$ appears to play an important role in the generation and maintenance of egg induced granuloma (Wille et al, 2004). The diminished focal and systemic production of TNF- $\alpha$ may be implicated in the down modulation of the granulomatous response (Hawrylowicz and O' Garra, 2005).

In the last two decades, several efforts have been made to develop an effective vaccine against the Schistosoma spp. especially after the appearance of resistance against the commonly used drug praziquantel (Kuntz et al, 2007). The immunization of mice stimulates specific immunity which causes reduction in worm burden, tissue egg load and liver pathology (Romeih et al, 2008). The vaccination of mice with mixed different antigens (SEA+ CAP), (SEA + SWAP) and (CAP + SWAP) has an immunoprophylactic effect and may protect liver against infection through reduction in worm burden leading to the improvement of many liver enzymes (Ashour et al, 2004). Schistosoma vaccine could cause proliferation of splenocytes, induce immune protection to the host by upregulating CD4 (+) and CD8 (+) T cells and inhibit the apoptosis of splenocytes from mice (Xiang et al, 2013).

The aim of the current study was to highlight the relationship between serum TNF- $\alpha$ level and the hepatocytes induced apoptosis in vaccinated, Schistosoma mansoni challenged murine models, using this as a trial to assess the efficacy of combined crude antigens (CAP, SWAP and SEA) used as an anti schistosomal potential vaccine, so four studies like parasitological (Kato-Katz thick 
smear for egg count), histopa-thologial \{haematoxylin and eosin (H\&E) staining of hepatic sections \}, histochemical (Feulgen staining of the hepatocytes DNA) and serological (ELISA to estimate serum TNF- $\alpha$ level) were per-formed.

\section{Materials and Methods}

Type of study: Experimental case control study conducted from 11/2013 to $5 / 2014$ at the laboratories of Medical Parasitology Department, Faculty of Medicine, Zagazig University and the Theodor Bilharz Research Institute, Giza, Egypt.

Animals: Fifty-two clean laboratory bred Albino male mice (aged 6 to 8 weeks and weighing 18 to $20 \mathrm{gm}$ each), were used. Mice were fed on standard diet with free accessibility to water and in standard cages all over the study time at the Schistosome Biological Supply Program (SBSP), Theodor Bilharz Research Institute (TBRI), Giza, Egypt.

Infective cercariae: Laboratory bred Biomphalaria alexandrina were purchased from the Shistosome Biological Supply Unit, Theodore Bilharz Research Institute. After exposure to light for at least 4 h, S. mansoni cercariae (Egyptian strain) shed from the snails were used to infect the experiment's mice through the subcutaneous route injection (Peters and Warren, 1969).

The crude schistosomal antigens preparation: The cercarial antigen preparation (CAP) soluble worm antigen preparation (SWAP) and soluble egg antigen (SEA) were prepared at the SBSP of (TBRI). CAP was prepared according to the method of Carter and Collely (1979), SWAP was prepared according to the method of Salih et al. (1978) and SEA was prepared according to Boros and Warren (1970), a combined preparation of these three antigens (CAP, SWAP and SEA) was tested as a potential vaccine. The total protein content of the combined antigens preparation was determined by the method of Bradford (1976).
Freund's adjuvant (Adj) \{Freund's complete adjuvant (FCA) and Freund's incomplete adjuvant (FIA) $\}$ was obtained from Sigma Chemical Co., St Louis, Mo, USA and emulsified in the phosphatebuffered saline (PBS) at a ratio of 2:1 $(\mathrm{v} / \mathrm{v})$. The vaccination schedule was performed according to Nabih and Soliman (1986). Each mouse was sensitized with an initial subcutaneous injection of $200 \mu \mathrm{l}$ of the combined antigens with total protein concentration $30 \mu \mathrm{g}$ protein. After two weeks, a second S.C. injection of 200 $\mu l$ of same antigens was given containing $20 \mu \mathrm{g}$ protein; hence each mouse received a total antigen dose of $50 \mu \mathrm{g}$ protein. The antigens were combined with Freund's adjuvant (Complete for the first injection, Incomplete for the boost) subcutaneously at a 1:1 ratio $(\mathrm{v} / \mathrm{v})$, i.e. boosted twice at 2weeks interval (Smithers et al, 1989).

The adjuvant control group was injected by the adjuvant only without any antigens following the same schedule. The infection was done by subcutaneous injection into each mouse with $\pm 60 \mathrm{~S}$. mansoni cercariae suspended in $0.2 \mathrm{ml}$ solution, after 3 weeks from the first S.C injection (Peters and Warren, 1969).

Experimental design: Four groups of Albino male mice (13 mice in each group) were used in this study. Group 1(G1) as normal control, G2 as infected control while G3 supported by Freund's Adjuvant (F. Adj) then infected and G4 vaccinated with combined antigens (CAP, SWAP and SEA) + F. Adj then infected. Animals were sacrificed by cervical dislocation 9 weeks post infection and parasitological, histopathologial, histochemical, and serological studies.

Egg counts: starting from $5^{\text {th }}$ week post infection (to confirm infection), stools samples from all groups were collected for Kato-Katz thick smear for egg count weekly till the end of the study (Katz et $a l$, 1972), and the mean egg count was calculated. The vaccine protection degree was highlighted by \%Reduction (\%R) after (Tendler et al., 1986): 


$$
\begin{gathered}
\begin{array}{c}
\text { Mean egg count } / \mathrm{g} \text { stools of control's }(\mathrm{G} 2)- \\
\text { Mean egg count } / \mathrm{g} \text { stools of test's }
\end{array} \\
\text { Mean egg count } / \mathrm{g} \text { stools of control }(\mathrm{G} 2)
\end{gathered}
$$

Histopathological study: Formalin- counting was carried out in 5 successive fixed paraffin (10\%) embedded liver microscopic fields/10 low power field tissues $(4 \mu \mathrm{m}$ cut) were prepared and stained with (haematoxylin and eosin, H\&E) according to Von Lichtenberg (1962). Number and diameter of Schistosoma granulomas were calculated. The (LPF) in serial tissue sections of more than 250um apart (Farah et al, 2000). The vaccine protection degree was highlighted by \%Reduction (\%R) after Tendler et al. (1986):

Mean diameter or (no.) of control's (G2)Mean diameter (no.) of test's

$\%$ reduction $=$ $\mathrm{x} 100$

Mean diameter (no.) of control group (G2)

Histochemical study: Formalin-fixed paraffin $(10 \%)$ embedded liver tissues ( $4 \mu \mathrm{m}$ cut) were prepared and stained with Feulgen stain which is used to identify chromosomal material or DNA changes in hepatocytes. It depends on DNA acid hydrolysis (Chieco and Derenzini, 1999); DNA stained bright red in normal hepatocytes. Faint red staining of liver cell DNA denotes (marked apoptosis); while pale red staining of liver cell DNA means (moderate apoptosis) and less than bright red staining of liver cell DNA denotes (mild apoptosis) (Etewa et al, 2013).

Serological study: For estimation of Serum TNF- $\alpha$, blood was drawn from the corner of mouse's eyes of all the groups. Sera were separated and stored at $-20^{\circ} \mathrm{C}$ until the determination of serum TNF- $\alpha$ level by enzyme linked immunosorbent assay (ELISA). Serum TNF- $\alpha$ was determined by ELISA according to the manufacturer's instructions. For quantitative detection of mouse TNF- $\alpha$, assay used immunoassay technique by mouse TNF- $\alpha$ Platinum ELISA (eBioscience BMS607/ 2/BMS607/2TWO/BMS607/2TENEurop e/international). Optical density (OD) values were measured at $450 \mathrm{~nm}$, Cytokine level was calculated by using the standard curve constructed with serial dilution of the standard of cytokine in $(\mathrm{pg} / \mathrm{ml})$.

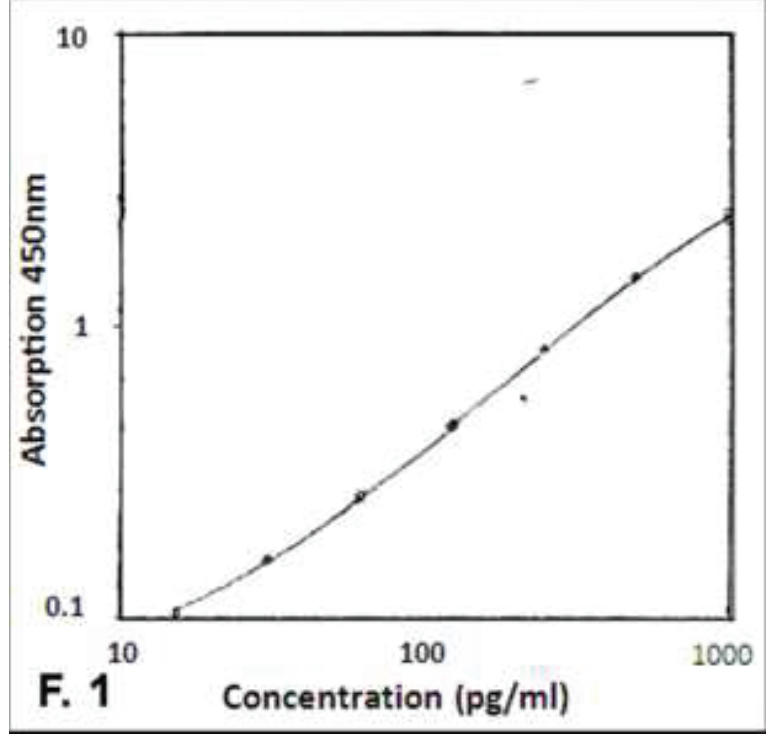

Fig. 1: Standard curve of mouse TNF- $\alpha$ ELISA. 
Ethical aspects: All procedures related to animal experimentation in the present study met the International Guiding Principles for Biomedical Research Involving Animals as issued by the International Organizations of Medical Sciences and this study was approved by the ethics committee of the Faculty of Medicine, Zagazig University.

Statistical analysis: All data were subjected to statistical analysis using SPSS win statistical package version 20 . T test was used for comparison between means of two groups. $\mathrm{P}$ value was set at $<0.05$ for significant results and $<0.001$ for high significant results.

\section{Results}

Parasitologically reduction was recorded in mean egg counts/g stools by Kato Katz technique in vaccinated group with combined antigens (G4) compared to control infected group (G2) with significant difference $(\mathrm{p}<0.05)$, and statistically insignificant reduction in mean egg counts/g stools recorded in (G3) compared to $\mathrm{G} 2(\mathrm{P}>0.05)$.

Histopathologically G4 showed marked reduction in the mean granuloma number and diameter compared to G2 with high significant difference $(\mathrm{p}>0.001)$, statistically insignificant reduction in mean granuloma number and diameter recorded in G3compared to G2 ( $\mathrm{P}>0.05)$.

Fuelgen histochemical study: for assessment of induced apoptosis in hepatocytes of the tested and control groups of mice, it was found that in the infected control group (G2), S. mansoni induced marked hepatocytes apoptosis with faint red staining of hepatocytes in comparison with normal mice hepatocytes whose normal DNA showed bright red staining. Moderate apoptosis occurred in (G3), showed pale red staining. While mild apoptosis occurred in combined vaccineted group (G4) marked by less bright red staining.

Serum TNF- $\alpha$ level showed significant reduction in $\mathrm{G} 4$ compared to $\mathrm{G} 2(\mathrm{P}<0.05)$ and statistically insignificant reduction in G3 compared to G2 $(\mathrm{P}>0.05)$.

In the current study, we detected that (G4) combined antigens (CAP, SWAP and SEA) are inversely proportional to mean egg counts/g stools, granuloma number \& size and the serum level of TNF- $\alpha$. The details are given in tables (1 to 4 ) and figures (1 to 12).

Table 1: Mean egg count for eggs per gram stools (EPG) by Kato Katz as detected till week 9 post-infection in control and tested groups.

\begin{tabular}{|c|c|c|c|}
\hline Parameter & $\begin{array}{c}\text { egg count/g stools } \\
\mathrm{M} \pm \mathrm{SD}\end{array}$ & PReduction \\
\hline Groups & -- & -- & -- \\
\hline G1 & $435.23 \pm 53.22$ & -- & -- \\
\hline G2 & $412.26 \pm 34.19$ & $5.28 \%$ & $>0.05$ \\
\hline G4 & $126.78 \pm 12.37 *$ & $70.87 \%$ & $<0.05$ \\
\hline
\end{tabular}

Insignificant difference from infected control at $\mathrm{p}>0.05$, *Significant difference from infected control at $\mathrm{p}<0.05$.

Table 2: Granulomas number and diameter (um) \& \% reduction at week 9 post-infection in control and tested groups.

\begin{tabular}{|c|c|c|c|c|}
\hline $\begin{array}{c}\text { Parameter } \\
\text { Groups }\end{array}$ & $\begin{array}{c}\text { granulomas number } \\
(/ 10 \mathrm{LPF}) \mathrm{M} \pm \mathrm{SD}\end{array}$ & $\begin{array}{c}\% \\
\text { Reduction }\end{array}$ & $\begin{array}{c}\text { granulomas diameter } \\
\text { (um) M } \pm \mathrm{SD}\end{array}$ & $\begin{array}{c}\% \\
\text { Reduction }\end{array}$ \\
\hline G1 & - & - & - & - \\
\hline G2 & $52.66 \pm 8.15$ & - & $334.47 \pm 32.31$ & - \\
\hline G3 & $49.98 \pm 8.09$ & $5.09 \%$ & $323.24 \pm 28.16$ & $3.36 \%$ \\
\hline G4 & $14.34 \pm 3.79 * * *$ & $72.77 \%$ & $135.26 \pm 15.44 * * *$ & $59.56 \%$ \\
\hline
\end{tabular}

*** High significant difference from infected control at $\mathrm{p}<0.001$. 
Table 3: Serum TNF $-\alpha$ level at week 9 post-infection in control and tested groups.

\begin{tabular}{|c|c|c|c|c|}
\hline $\begin{array}{c}\text { Groups } \\
\text { parameter }\end{array}$ & G1 & G2 & G3 & G4 \\
\hline Range & $90-93$ & $400-470$ & $400-470$ & $100-160$ \\
\hline $\mathrm{TNF}-\alpha(\mathrm{pg} / \mathrm{ml}) \mathrm{M} \pm \mathrm{SD}$ & $1.188 \pm 2.45$ & $5.610 \pm 3.66$ & $5.550 \pm 3.23$ & $1.570 \pm 2.67 *$ \\
\hline $\mathrm{P}$ & - & - & $>0.05$ & $<0.05$ \\
\hline
\end{tabular}

Insignificant difference from infected control $(>0.05), *$ Significant difference from infected control $(<0.05$.

Table 4: Comparison among different methods used for evaluation of used combined antigens.

\begin{tabular}{|c|c|c|c|c|}
\hline $\begin{array}{c}\text { parameter } \\
\text { Groups }\end{array}$ & $\begin{array}{c}\text { egg count/g } \\
\text { stools }\end{array}$ & $\begin{array}{c}\text { granulomas number } \\
(/ 10 \mathrm{LPF})\end{array}$ & $\begin{array}{c}\text { granulomas diameter } \\
\text { (um) }\end{array}$ & $\begin{array}{c}\text { TNF- } \alpha \\
(\mathrm{pg} / \mathrm{ml})\end{array}$ \\
\hline G1 & -- & -- & -- & $1.188 \pm 2.45$ \\
\hline G2 & $435.23 \pm 53.22$ & $52.66 \pm 8.15$ & $334.47 \pm 32.31$ & $5.610 \pm 3.66$ \\
\hline G3 & $412.26 \pm 34.19$ & $49.98 \pm 8.09$ & $323.24 \pm 28.16$ & $5.550 \pm 3.23$ \\
\hline G4 & $126.78 \pm 12.37^{*}$ & $14.34 \pm 3.79 * * *$ & $135.26 \pm 15.44^{* * *}$ & $1.570 \pm 2.67 *$ \\
\hline
\end{tabular}

Results of (G4) combined antigens (CAP, SWAP and SEA) compared to G2 showed, high significant difference regarding granuloma number $\&$ size and significant difference with results of egg count, and serum TNF- $\alpha$ level.

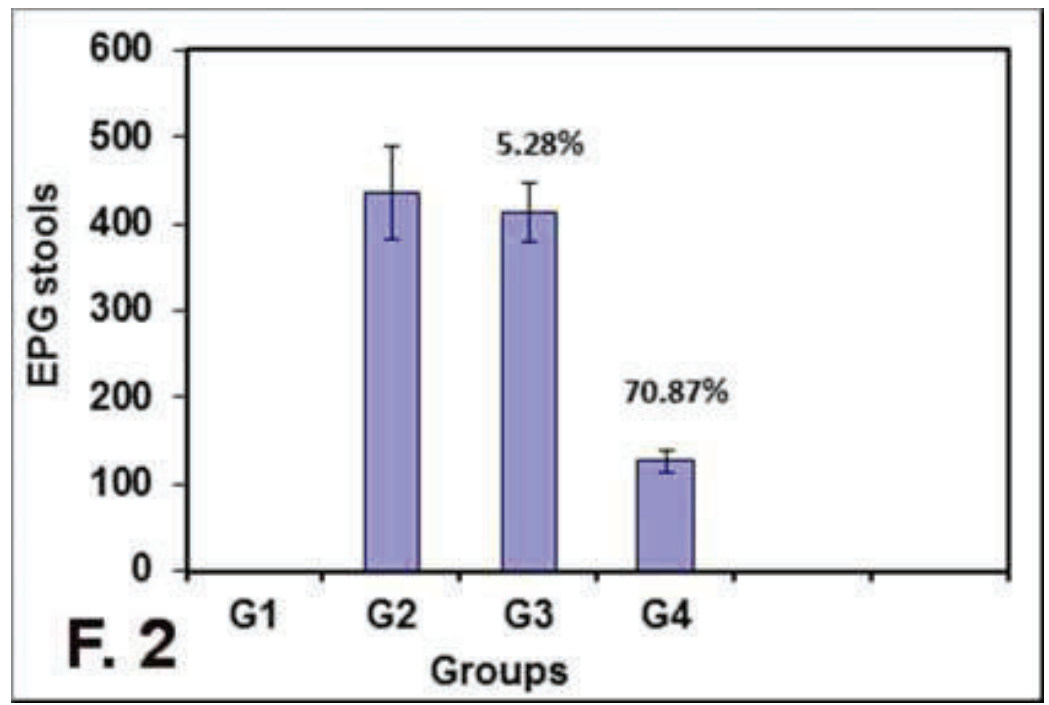

Fig 2: Mean egg count for eggs per gram stools (EPG) by Kato Katz detected till week 9 post-infection in control and tested groups.

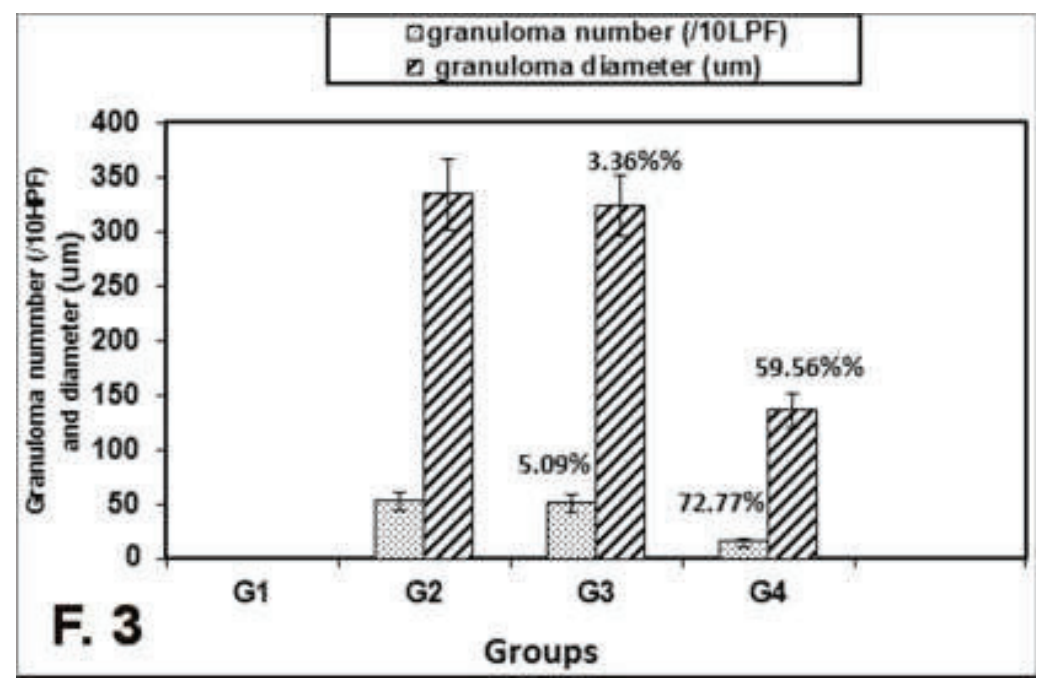

Fig. 3: Granulomas number (/10LPF), diameter (um) and \% reduction at week 9 post-infection in control and tested groups. 


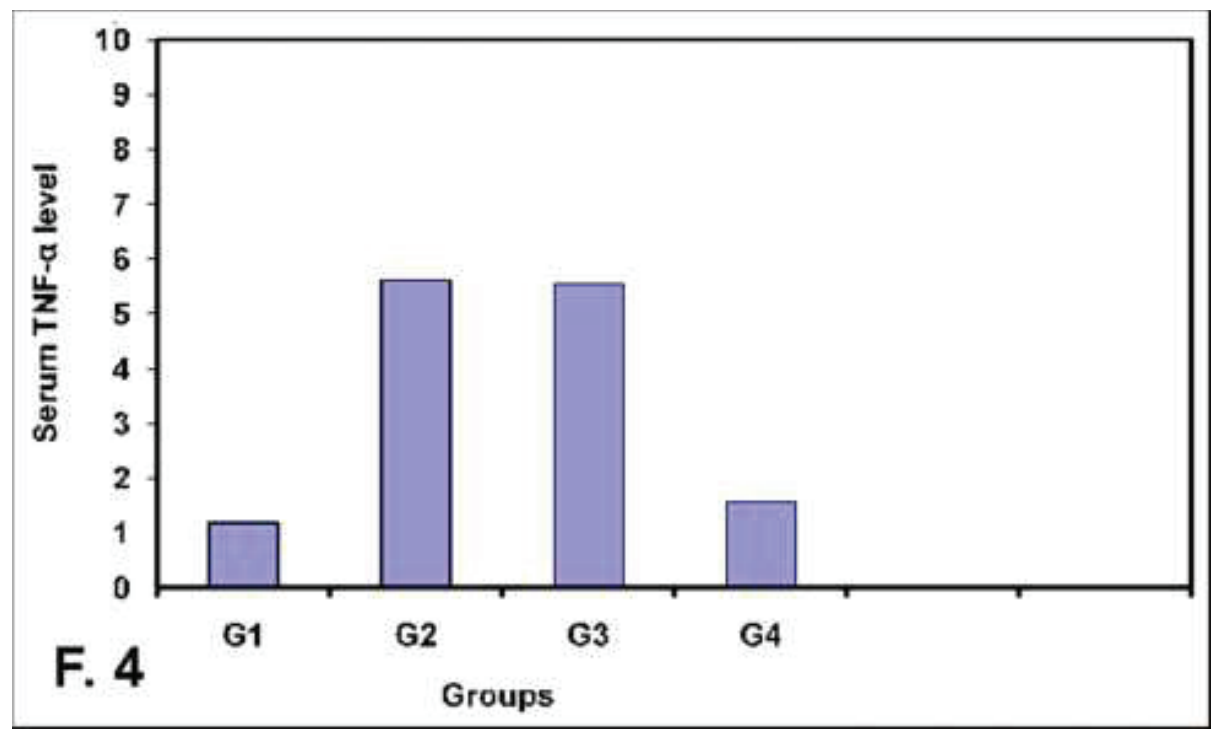

Fig. 4: Serum TNF $-\alpha$ level at week 9 post-infection in control and tested groups.

\section{Discussion}

In the parasitological study, a significant reduction in the fecal egg count and the highest had been in (G4) combined antigens (CAP, SWAP and SEA), an insignificant reduction was found in (G3) supported by Freund's adjuvant only then infected, compared to G2; this indicated that Freund's adjuvant had no protective effect alone, while the combined vaccine + Adj was effective leading to decrease stools egg count, so a reduction of schistosomiasis morbidity was achieved. This may attributed to induced immune responses leading to decrease in parasite load and reduced egg production. Obviously, further research is required on the development of novel adjuvant vehicles as well as cocktail vaccine formulations to enhance protection levels with eventual aim of $100 \%$ worm reduction (Siddiqui et al, 2011).

Kato-Katz technique is sensitive and accurate method for worm burden and the intensity of infection (Doenhoff et al, 2004). Also, Teixeira et al. (2007) stated that Kato-Katz method is the cornerstone for diagnosis of $S$. mansoni infection, with a simple inexpensive procedure, and widespread use in endemic areas of intestinal schistosomiasis.
In the present study, high significant decrease in granuloma number and size were detected in G4 (combined antigens group) $(72.77 \% \& 59.56 \%$ respectively) and lower insignificant reductions were found in G3, compared to G2. While, ElMarhoumy et al. (2009) detected significant reduction in mean number \& size of granulomas in the liver $(92.92 \%$ \& $43.53 \%$ respectively) when used autoclaved cercarial vaccine. This diffe-rence in results is attributed to the differ-ences in the used antigens. Besides, Martins et al. (2012) detected that immunization of mice with glycosylphosphatidylinositol (GPI) anchored proteins (from the outer surface of live adult $S$. mansoni worms) induced a mixed Th1/Th2 type of immune response with production of IFN- $\gamma$ and TNF- $\alpha$, and low levels of IL-5 into the supernatant of the splenocyte cultures. The protection engendered by this vaccination protocol was confirmed by $29 \%$ reduction in the number of the granulomas per area.

In the current work, the use of Fuelgen histochemical technique was for highlighting the induced apoptosis in heaptocytes of the tested and control groups of mice, the results showed that in infected control group (G2), there was marked induced hepatic cell apoptosis (Fig. 10) in comparison with normal mice hepato- 
cytes whose normal DNA showed bright red staining (Fig. 9). Moderate apoptosis occurred in G3 (Fig. 11) while mild apoptosis occurred in G4 (Fig. 12). These changes may be attributed to grades of functional damage of hepatocytes DNA and its metabolism induced by hepatic schistosomaisis. These findings were supported by the explanation of Kumar et al. (2009) that apoptosis is a pathway of cell death induced by a suicidal program in which cells destined to die activate enzymes that degrade the cell nuclear DNA. It is also a pathologic event when diseased cells become damaged beyond repair and are eliminated without eliciting a host reaction, thus limiting collateral tissue damage (Fadeel and Orrenius, 2005).

The ability of helminths, such as schistosomes, to manipulate the host's immune system is an essential part of their survival and is done to avoid excessive immune responses (Ritter et al, 2010).In schistosomiasis, deposition of eggs in liver induces a severe inflamematory reaction, which participates in elimination of egg but may at the same time cause damage of DNA and liver cell apoptosis (Sayed et al, 2006). It was suggested that schistosome worms may use apoptosis as a survival strategy to establish infection in their host, and can influence the development or maintenance of different clinical manifestations (Lundy et al, 2001).

Conversely, Haseeb et al. (1996) showed that in $S$. mansoni females the egg-laying process is decreased and the tyrosine uptake is increased in the presence of TNF- $\alpha$. There is controversial evidence of TNF- $\alpha$ influence on the parasite's metabolism, and the molecular mechanisms of its action have never been explored (Oliveira et al, 2009).

An important point to be considered in $S$. mansoni TNF- $\alpha$ signaling pathway is the presence of Caspases 3 and 8 and C-IAP protein. Classically, caspases 3 and 8 are involved in the apoptosis process induced by TNF- $\alpha$ signaling and are inhibited by c-IAP. No direct evidence exists so far in the literature for the apoptosis process in schistosomes (Oliveira et al, 2009).

However, the current results showed that G4 (combined antigens group) there was significant decrease in TNF- $\alpha$ serum level compared to (G2) control infected, and insignificant decrease in G3 compared to G2. These results are understood if we consider the findings of Amiri et al. (1992) who reported that TNF- $\alpha$ induces liver granulomas and egg-laying of parasites in vivo; additionally, Cheever et al. (1999) observed that egg laying and fecundity were delayed when SCID immuno deficient schistosome-infected mice were studied, suggesting the possibility that the delay in fecundity is due to a delay in tissue produced TNF- $\alpha$ in SCID mice, nevertheless, their data provided little evidence that TNF- $\alpha$ alone can reconstitute early fecundity in this infected-mouse model.

Moreover, TNF- $\alpha$ is also one of the most important host cytokines involved in the inflammatory response. When cercariae, the infective stage, penetrates the human skin the release of TNF- $\alpha$ is started (Oliveira et al, 2009). During the penetration process, cercariae will be exposed to host TNF- $\alpha$ in the skin and this could act to promote parasite survival and development, in a similar manner as described in adult worms by Davies et al. (2004).

The current results showed that combined antigens (G4) was associated with significant decrease egg count/g stools and serum TNF- $\alpha$ levels, with high significant decrease in granuloma numbers \& diameters, in addition to, the induced apoptosis in hepatocytes. So, the results agreed with $\mathrm{Hsu}$ et al. (1995) who detected that the TNF-receptor protein stimulation was associated with cell death. Also, Haseeb et al. (1996) recorded that recombinant TNF- $\alpha$ was associated with decrease Schistosoma female fecundity, and this affect egg 
count/ g stool. Ramadan et al. (2013) reported that TNF- $\alpha$ had a role in $S$. mansoni infection that could progress to cirrhotic liver. Whereas, Lundy et al. (2001) found that SEA stimulate T helper lymphocytes apoptosis and this will decrease the cytokines production included TNF- $\alpha$. In addition, Rimkunas et al. (2009) emphasized that TNF- $\alpha$ plays an important role in hepatocytes apoptosis. In contrast, Hoffman et al. (1998) concluded that TNF- $\alpha$ was required to maintain reduced liver pathology in mice vaccinated with $S$. mansoni eggs. Yamada et al. (1998) decided that liver regeneration in mice requires type $1 \mathrm{TNF}-\alpha$ receptors. Davis et al. (2004) reported the involvement of TNF- $\alpha$ in limiting liver pathology and promoting parasite survival in schistosome infection.

The present results showed that vaccination with combined crude antigens (CAP, SWAP \& SEA+Adj) gave protective effects on hepatocytes of $S$. mansoni infected mice by decreasing serum level of TNF- $\alpha$ and hepatocytes induced apoptotic changes, as TNF- $\alpha$ plays a complex role in the pathophysiological changes caused by schistosomiasis. These data agreed with Hoffmann et al. (1998) who found that immunization using soluble egg antigen (SEA) only from $S$. mansoni gave immunity in mice, thus protecting the mice from challenge by $S$. mansoni cercariae, this protective effect manifested by the reduction in parasitological parameters, increased levels of specific immunoglobulins. While their findings that raised hepatic mRNA expression of TNF- $\alpha$ and TGF- $\beta$, TNF- $\alpha$ play an important role in the generation and maintenance of egg induced granuloma is against the present data that might be due to difference in the used antigen. This protective immunity was characterized as the SEA-specific T-cell proliferation accompanied by IFN- $\gamma$ and IL-2 production and cytotoxic $\mathrm{CD} 8^{+} \mathrm{T}$-cell activetion that contributed to the marked reduction in the number of granulomas and the fibrosis amount led to mice survival (ElAhwany et al, 2012). SEA can suppress TNF- $\alpha$ and IL-6 secretion (Ritter et al, 2010) that agreed with the present results.

Silveira-Lemos et al. (2013) found that after in Vitro SEA stimulation in Tlymphocytes culture, increased synthesis of TNF- $\alpha$ by CD4+ T lymphocytes in acute schistosomiasis mansoni infected patients. TNF- $\alpha$ does appear to mediate protection from excessive hepatocellular damage and cachexia, and is not the cause of hepatocyte apoptosis (Davies et al, 2004).

$\mathrm{Xu}$ et al. (2009) added also that SEA, rather than other antigens, may be responsible for the apoptotic changes observed after eggs deposition. Xu et al. (2010) reported that Schistosoma non-egg antigens (SWAP) trigger Th2 cell apoptosis, contributed to Th1 polarization, which was associated with worm clearance and severe schistosomiasis. Meanwhile, after adults lay eggs, the egg antigens trigger Th1 cell apoptosis via the caspase pathway, contributing to Th2 polarization, which is associated with mild pathology and enhanced survival of both worms and their hosts. So, apoptosis is preferentially induced by different schistosome antigens CAP, SWA \& SEA during different stages of infection. So, the apoptosis may contribute an additional mechanism that modulates immune interaction between hosts and parasites.

\section{Conclusion}

Generally speaking, schistosomiasis is more or less a worldwide problem.

The detection of the combined antigens (CAP, SWAP and SEA + F. Adj) is a promising a good anti-schistosomal potential vaccine regarding its protective role of the hepatocytes by decreasing the induced apoptosis and serum TNF- $\alpha$. Besides, the serum level of TNF- $\alpha$ is directly proportional to the degree of apoptosis. The combined antigens (CAP, SWAP \& SEA) presented protection to hepatocytes DNA is inversely propor- 
tional to the TNF- $\alpha$ serum level and the apoptosis degree.

The outcome results divert the attention to a new line of protection by the antiTNF- $\alpha$ to prevent its hazards as a trial to decrease hepatocytes induced apoptosis

\section{Explanation of figures}

Fig. 5: Normal control (G1) a cut section of liver-showing normal hepatic architecture (H\&E x100).

Fig. 6: Control infected (G2) a cut section of liver-showing large number of schistosome' granulomas (cellular, fibrocellular and fibrous) (H\&E, X200).

Fig. 7: Control Adj +infected (G3) a cut section of liver-showing many schistosome' granulomas (cellular, fibrocellular and fibrous) (H\&E, X200).

Fig. 8: Combined (G4) a cut section of liver showing decrease in bilharzial granulomas number and diameter (H\&E, X200).

Fig. 9: Normal control (G1) a cut section of liver with normal Feulgen reaction denoting normal DNA content in nuclei of hepatocytes, DNA stained bright red (Feulgen stain, $\mathrm{x} 200$ ).

Fig. 10: Control infected (G2) a cut section of liver with Feulgen reaction showing reduced DNA content in numerous nuclei of hepatocytes with numerous pyknotic nuclei of hepatocytes and faint red staining of liver cell DNA due to marked apoptosis (arrows) (Feulgen stain, x 200). Fig. 11: F. Adj + infected control (G3) a cut section of liver with Feulgen reaction showing reduced DNA content in some nuclei of hepatocytes, pale red staining of liver cell DNA due to moderate apoptosis (arrows) (Feulgen stain, $\mathrm{x} 200$ ).

Fig. 12: Combined+Adj (G4) a cut section of liver with Feulgen reaction showing reduced DNA content in few nuclei of hepatocytes, less than bright red staining of hepatocytes DNA due to mild apoptosis (arrows) (Feulgen stain, x 200). 


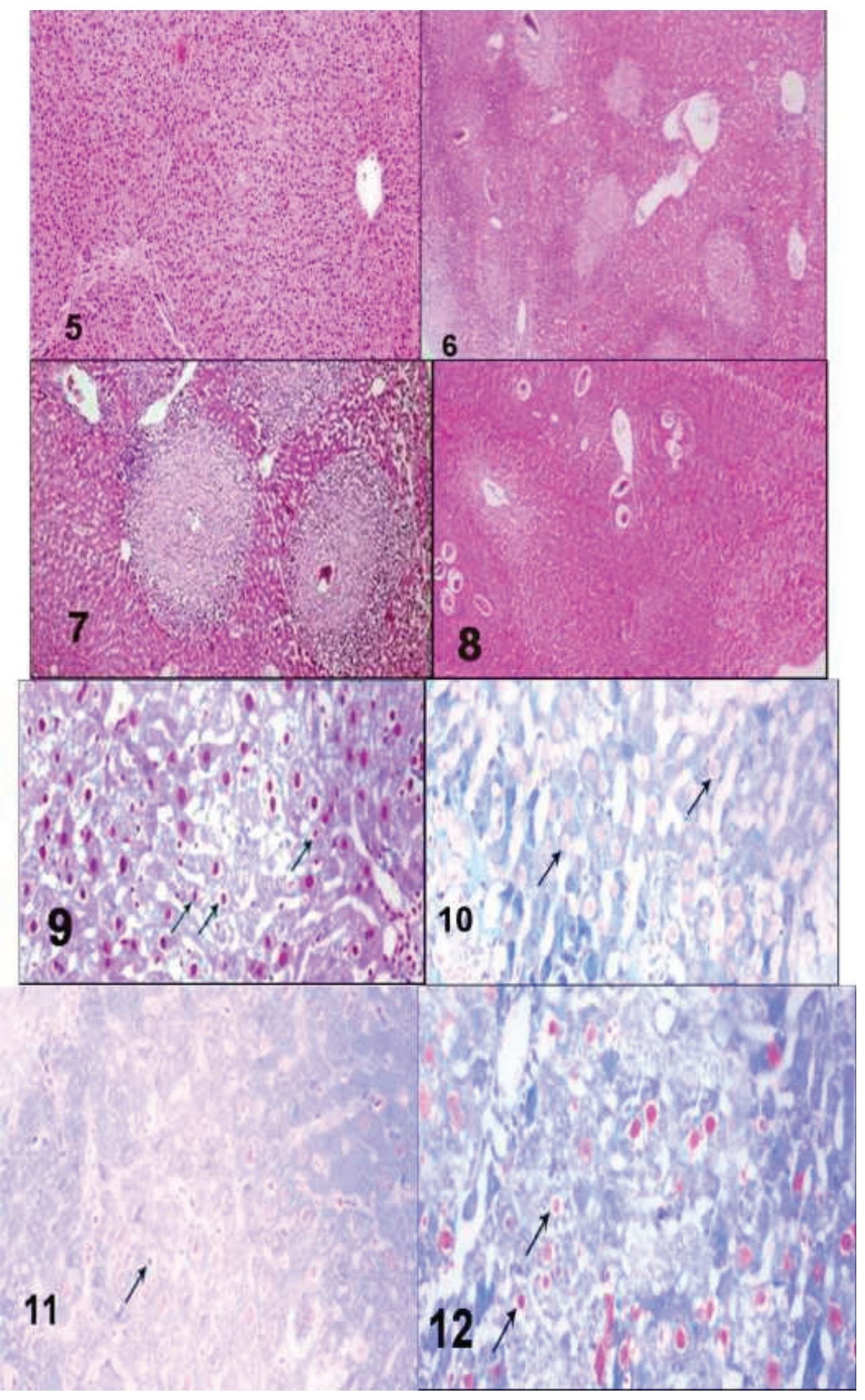




\section{References}

Amiri, P, Locksley, RM, Parslow, TG, Sadick, M, Rector, E, et al, 1992: Tumour necrosis factor alpha restores granulomas and induces parasite egg-laying in schistose-meinfected SCID mice. Nature 356:604-7.

Ashour, AA, Ahmed, SA, Maghraby, AS, Zahran, HG, 2004: Immunoprophylactic effect of single and mixed schistosomal antigens on Schistosoma mansoni infected mice. Egypt J. Hosp. Med. 14:86-103.

Boros, DL, Warren, KS, 1970: Delayed hypersensitivity type III: Granuloma formation and dermal reaction induced and elicited by a soluble factor isolated from Schistosoma mansoni eggs. J. Exp. Med. 132: 488-507.

Bradford, MM, 1976: A rapid and sensitive method for the quantitation of microgram qualities of protein utilizing the principle of protein dye binding. Anal. Biochem. 72:24854.

Carter, CE, Collely, DG, 1979: Partial purification of Schistosoms mansoni soluble egg antigen with ConSepharase chromatography. J. Immunol. 122:2204-9.

Cheever, AW, Poindexter, RW, Wynn, T A, 1999: Egg laying is delayed but worm fecundity is normal in SCID mice infected with Schistosoma japonicum and S. mansoni with or without recombinant tumor necrosis factor alpha treatment. Infect. Immun. 67: 2201-8.

Chieco, P, Derenzini, M, 1999: The Feulgen reaction 75 years on. Histochem. Cell Biol. 111, 5:345-58.

Davies, SJ, Lim, KC, Blank, RB, Kim, JH, Lucas, KD, et al, 2004: Involvement of TNF in limiting liver pathology and promoting parasite survival during schistosomiasis infection. Int. J. Parasitol. 34:27-36.

Doenhoff, MJ, Chiodini, PL, Hamilton, J V, 2004: Specific and sensitive diagnosis of schistosome infection: can it be done with antibodies? Trends Parasitol. 20:35-9.

El-Ahwany, E, Bauiomy, I.R, Nagy, F, Zalat, R, Mahmoud, O, et al, 2012: T Regulatory cell responses to immunization with a soluble egg antigen in Schistosoma mansoniinfected mice. Korean J. Parasitol. 50, 1:2935.

El-Marhoumy, SM, El-Nouby, KA, Emara, MA, Abou-Rayia, DM, 2009: An experimental study for evaluating the efficacy of cercarial vaccine against Schistosoma mansoni. J. Egypt Soc. Parasitol. 39, 3:917-32.

Etewa, SE, EI Settawy, MA, Sadeek, GS, 2013: Potential role of interleukin 4 and 12 as adjuvants to tegumental antigen in a vaccination model for murine schistosomiasis mansoni. P.U.J., 6, 1:65-76.

Fadeel, B, Orrenius, S, 2005: Apoptosis: A basic biological phenomena with wide-ranging implications in human disease. J. Int. Med. 258, 6:479-517.

Farah, I.O, Johansson, M, Bengtson, K, Hau, J, 2000: Schistosoma mansoni in mice: the pattern of primary cercarial exposure determines whether a secondary infection post-chemotherapy elicits a $\mathrm{T}$ helper 1 - or a $\mathrm{T}$ helper 2-associated immune response. Scand. J. Immunol. 51:237-43.

Fairfax, KC, Amiel, E, King, IL, Freitas, TC, Mohrs, M, et al, 2012: IL-10R blockade during chronic schistosomiasis mansoni rests in the loss of B cells from the liver and the development of severe pulmonary disease. PLoS Pathog. 8, 1:e1002490.

Gores, GJ, Kaufmann, SH, 2001): Is TRAIL hepatotoxic? Hepatology 34:3-6.

Gryseels, BK, Clerinx, PJ, Kestens, L, 2006: Human schistosomiasis. Lancet, 368, 9541:1106-18.

Haseeb, MA, Solomon, WB, Palma, JF, 1996: Schistosoma mansoni: effect of recombinant tumor necrosis factor alpha on fecundity and (14C)-tyrosine uptake in females maintained in vitro. Comp. Biochem. Physiol. C. Pharmacol. Toxicol. Endocrinol. 115: 265-9.

Hawrylowicz, CM, O'Garra, A, 2004: Potential role of interleukin-10-secreting regulatory $\mathrm{T}$ cells in allergy and asthma. Nat. Rev. Immunol. 5:271-83.

Hoffman, KF, Caspar, P, Cheever, AW, Wynn, TA, 1998: IFN-gamma, IL-12, and TNF-alpha are required to maintain reduced liver pathology in mice vaccinated with Schistosoma mansoni eggs and IL-12. J. Immunol. 161:4201-10.

Hsu, H, Xiong, J, Goeddel, DV, 1995: The TNF receptor 1 -associated protein TRADD signals cell death and NF-kappa B activation. Cell 81:495-504.

Katz, N, Chaves A, Pellegrino, J, 1972: A simple device for quantitative stools thick smear technique in schistosomiasis mansoni. Rev Inst. Med. Trop. S Paulo 14:397-400. 
Kilicarslan, A, Kahaman, A, Akklz, H, Yildiz, F, et al, 2009): Apoptosis in selected liver diseases. Turkish .J. Gastroenterol. 20, 3:171-9.

Kroemer G, El-Deiry WS, Golstein P, et al, 2005: Classification of cell death: recommendations of the nomenclature committee on cell death. Cell Death Differ, 12, 2: S1463-7.

Kumar, V, Abbas, A, Fausto, N, Aster, J, 2009: Cellular responses to stress and toxic insults: Adaptation, injury and death. In: Robbins and Cortan Pathologic Basis of Diseases. $8^{\text {th }}$ edition.

Kuntz, AN, Davioud-Charvet, E, Sayed, A A, et al, 2007: Thioredoxin glutathione reductase from Schistosoma mansoni: An essential parasite enzyme and a key drug target. PloS Med. 4, 6:206-12.

Lundy, S, Lerman, SP, Boros, DL, 2001: Soluble egg antigen stimulated $\mathrm{T}$ helper lymphocyte apoptosis and evidence for cell death mediated by Fasel (+) Tand B cells during murine Schistosoma mansoni infection. Infect. Immun. 69, 1:271-80.

Martins, VP, Pinheiro, CS, Figueiredo, B CP, Assis, NRG, Morais, SB, et al, 2012: Vaccination with enzymatically cleaved GPIAnchored proteins from Schistosoma mansoni induces protection against challenge infection. Clin. Dev. Immunol. 21:96253849.

Nabih, I, Soliman, AM, 1986: Studies on fresh water snails, specific intermediate host for schistosomiasis. II. Isolation of total protein from native and irradiated snails. Cell Mol. Biol. 32:315-7.

Oliveira, KC, Carvalho, MLP, Venancio, TM, Miyasato, PA, Kawano, T, et al, 2009: Identification of the Schistosoma mansoni TNF-Alpha Receptor Gene and the Effect of Human TNF-Alpha on the Parasite Gene Expression Profile. PLoS Negl. Trop. Dis. 3, 12:e556.

Pearce, EJ, 2005: Priming of the immune response by schistosome eggs. Parasite Immunol. 27, 7/8:265-70.

Peters, AP, Warren, KS, 1969: A rapid method of infecting mice and other laboratory animals with Schistosoma mansoni subcutaneous injection. J. Par1sitol. 55:55863.

Ramadan, ME, Ramadan, ME, Yousef, M SM, 2013: Role of TNF alpha in Schisto- soma mansoni infection and cirrhotic liver. Intern. J. Pharmaceut. Med. Res. 1, 1:6-12.

Reiman, RM, Thompson, RW, Feng, CG, Hari, D, Knight, R, et al, 2006: Interleukin5 (IL-5) augments the progression of liver fibrosis by regulating IL-13 activity. Infect. Immun. 74, 3:1471-9.

Rimkunas, VM, Graham, MJ, Crooke, R M, Liscum, L, 2009: TNF-a plays a role in hepatocyte apoptosis in Niemann-Pick type C liver disease. J. Lipid Res. 50:327-33.

Ritter, M, Gross, O, Kays, S, Ruland, J, Nimmerjahn, F, et al, 2010: Schistosoma mansoni triggers Dectin-2, which activates the Nlrp3 inflammasome and alters adaptive immune responses. Proceed. Nat. Acad. Sci., United States of America; PNAS, 107:47-53.

Romeih, MH, Hassan, HM, Shousha, TS, Saber, MA, 2008: Immunization against Egyptian Schistosoma mansoni infection by multivalent DNA vaccine. Acta. Biochim. Biophys. Sin. (Shanghai), 40:327-38.

Rutherford, AE, Hynan, LS, Borges, CB, et $\boldsymbol{a l}$, 2007: Serum apoptosis markers in acute liver failure: A Pilot Study. Clin. Gastroenterol. Hepatol. 5, 12:1477-83.

Salih, SY, Bartlett, AD, Voller, A, 1978: Detection of antibodies by enzyme immunoassay in human schistosoma mansoni infections: a clinical and chemotherapeutic study. Tropenmed. Parasitol. 29, 4:409-12.

Sayed, AA, Cook, SK, William, DL, 2006: Redox balance mechanisms in Schistosoma mansoni relyon peroxiredoxins and albumin and impilicate peroxiredoxins as novel drug targets. J. Biol. Chemist. 281, 25:17001-10.

Siddiqui, AA, Bilal, A, Siddiqui, BA, Ganley-Leal, L, 2011: Schistosomiasis vaccines. Hum. Vaccin. 7, 11:1192-7.

Silveira-Lemos, D, Costa-Silva, MF, de Oliveira Silveira, AC, Batista, MA, Oliveira-Fraga, LA, et al, 2013: Cytokine pattern of $\mathrm{T}$ lymphocytes in acute Schistosomiasi smansoni patients following treated praziquantel therapy. J. Parasitol. Res. Volume 2013, Article ID 909134, 13 pages. http:// dx.doi.org/10.1155/2013/909134

Singh, K.P.; Gerard, H.C.; Hudson, A.P.; Boros, D.L. (2004): Expression of matrix metalloproteinases and their inhibitors during the desorption of schistosome egg induced fibrosis in praziquantel-treated mice. Immunology, 111: 343-352.

Smithers, SR, Hackett, F, Ali, OP, Simpson, AJG, 1989: Protective immunization 
of mice against Schistosoma mansoni with purified adult worm surface membrane. Parasite Immunol. 11:301-18.

Teixeira, CF, Neuhauss, E, Bem, R, Romanzini, J, Graeff-Teixeira, C，2007: Detection of Schistosoma mansoni eggs in feces through their interaction with paramagnetic beads in a magnetic field. PLoS Negl. Trop. Dis. 1:e73.

Tendler, M, Pinto, RM, Oliveira, LA, Gebara, G, Katz, N, 1986: S. mansoni vaccination with adult worm antigens. Int. J. Parasitol. 16:347-52.

Thornberry, NA, 1998: Caspases: Key mediators of apoptosis. Chem. Biol. 5:R97-103.

Von Lichtenberg, FC, 1962: Host response to eggs of Schistosoma mansoni. I- Granuloma formation in the sensitized laboratory mouse. Am. J. Pathol. 41: 711-31.

WHO, 2010: Schistosomiasis Fact Sheet $\mathrm{N}^{\circ} 115$; www.who.int/mediacentre/factsheets/ fs 115/en/index.html; Updated February 2010.

Wille, U, Nishi, M, Lieberman, L, Wilson, EH, Roos, DS, 2004: Hunter CA. IL-10 is required to prevent immune hyperactivity during infection with Trypanosoma cruzi. Parasite Immunol. 26:229-36.

Xiang, J, Li, W, Zhang, L, 2013: Dynamic changes of proliferation, subsets and apoptosis of splenocytes from BALB/c mice immunized with recombinant $\mathrm{Bb}$ (pGEXSj26GST-Sj32) vaccine against Schistosoma japonicum. Xi Bao Yu Fen Zi Mian Yi Xue Za Zhi. (11):1129-32.

Xu, X, Wen, X, Chi, Y, Lei He, L, Sha Zhou, S, et al, 2010: Activation induced $T$ Helper cell death contributes to Th1/Th2 polarization following murine Schistosoma japonicum infection. J. Biomed. Biotechnol. Volume 2010, Article ID 202397, doi: 10. 1155/2010/202397, 12 pages. http: //dx. doi. org/10.1155/2010/202397

Xu, X, Zhang, D, Sun, W, et al, 2009: A Schistosoma japonicum chimeric protein with a novel adjuvant induced a polarized Th1 immune response and protection against liver egg burdens. BMC Infect. Dis. 9:54-9.

Yamada, Y, Webber, EM, Kirillova, I, et al, 1998: Analysis of liver regeneration in mice lacking type 1 or type 2 tumor necrosis factor receptor: requirement for type 1 but not type 2 receptor. Hepatology, 28:959-970. 